\title{
Correlation of serum homocysteine levels and pregnancy outcome: the dilemma continues
}

\author{
Noopur Jaiswal', Anjoo Agrawal ${ }^{1}$, Smriti Agrawal', ${ }^{1}$,inita Das ${ }^{1}$, \\ Amita Pandey ${ }^{1}$, Rajendra Singh ${ }^{2}$
}

\author{
${ }^{1}$ Department of Obstetrics \& Gynaecology, King George medical university, Lucknow, Uttar Pradesh, India \\ ${ }^{2}$ Central Drug Research Institute, Lucknow, Uttar Pradesh, India
}

Received: 30 November 2015

Revised: 13 January 2016

Accepted: 16 January 2016

\section{*Correspondence: \\ Dr. Anjoo Agrawal, \\ E-mail: anjooa@gmail.com}

Copyright: (C) the author(s), publisher and licensee Medip Academy. This is an open-access article distributed under the terms of the Creative Commons Attribution Non-Commercial License, which permits unrestricted non-commercial use, distribution, and reproduction in any medium, provided the original work is properly cited.

\section{ABSTRACT}

Background: Hyperhomocysteinemia has been implicated as a risk factor for complications in pregnancy including abortion, preeclampsia and placental abruption. The present study was designed to study the correlation, if any, of Hyperhomocysteinemia with pregnancy outcome.

Methods: Pregnant women between 14 to 24 weeks of gestation were included as subjects. Serum homocysteine levels and MTHFR gene (Methylenetetrahydrofolate reductase 677C>T) polymorphism was estimated. The women were followed till delivery and obstetric $\&$ neonatal outcomes were noted.

Results: A total of 81 women were followed till delivery. Out of these 42 women had an uncomplicated pregnancy and delivery and 39 women had at least one antenatal or perinatal complication. Difference between mean serum homocysteine in both the groups was not statistically significant $(\mathrm{p}=0.403)$. No significant difference was found in the occurrence of different genotypes in the 2 groups though women with TT genotype were found to have higher serum homocysteine levels as compared to other genotypes.

Conclusions: Though the serum homocysteine levels were higher in the women with pregnancy complications as compared to women without complications but the difference was not statistically significant.

Keywords: Homocysteine, Serum homocysteine level, Pregnancy complication, Hyperhomocysteinemia, MTHFR gene polymorphism

\section{INTRODUCTION}

Homocysteine, an amino acid, is a metabolite in methionine-cysteine pathway. It is metabolized in body to either cysteine using pyridoxine (vitamin $\mathrm{B}_{6}$ ) or it can be recycled to methionine using folic acid and methylcobalamin (Vitamin $\mathrm{B}_{12}$ ) as co factors. MTHFR (Methylenetetrahydrofolate reductase), is essential for metabolism of homocysteine to methionine. Activity of this enzyme is controlled by MTHFR gene. A base transition from Cytosine to Thiamine at nucleotide position 667 of this gene (C677T polymorphism) leads to production of 'Thermolabile Variant' of enzyme with reduced activity. Hyperhomocysteinemia is a condition characterized by high levels of homocysteine in blood and may arise either due to genetic defects in enzyme involved in metabolism, nutritional deficiency of vitamin cofactors, chronic medical conditions or certain drugs.

There is already a large body of evidence indicating that elevated plasma total homocysteine may be causally related to risk of coronary, cerebral and peripheral arterial diseases. ${ }^{1} \quad$ Studies have indicated that hyperhomocysteinemia may also be an important biological marker for, and possibly even a contributor to complications and adverse outcomes of pregnancy. ${ }^{2} \mathrm{~A}$ 
recent systematic review indicates that folate deficiency, hyperhomocysteinemia, and homozygosity for the MTHFR gene are probable risk factors for placentamediated diseases, such as preeclampsia, spontaneous abortion, and placental abruption. ${ }^{3}$ However, available data are not entirely satisfactory and prospective studies are needed to confirm these findings and to guide future research. Vollset et al conducted the Hordaland Homocysteine study (HHS) and found a raised homocysteine level is associated with increased risk of pregnancy complications like preeclampsia, preterm labour, very low birth weight, stillbirth, neural tube defects etc. The study of Vollset et al raised many research questions that need to be answered. Several studies have looked at association between homocysteine levels and pregnancy and neonatal outcomes however the results are inconclusive. ${ }^{2,4-8}$

The following study is a prospective study to explore the relation, if any between serum homocysteine levels in pregnancy and adverse maternal and fetal outcomes.

\section{METHODS}

\section{Subjects}

The study was conducted in the Department of Obstetrics and Gynaecology at King George's Medical University, Lucknow, India in collaboration with Central Drug Research Institute (CDRI), Lucknow India over a period of 1 year. After taking written informed consent, antenatal women between 14 to 24 weeks of gestation were included in the study. The study was approved by institute's ethical committee. Women with history of hypertension, diabetes mellitus, coagulopathies, or history of prolonged drug intake for other illness like metformin, proton pump inhibitor, phenytoin etc., were excluded. Women with history of smoking, alcohol intake were also excluded from the study. Complete history including detailed dietary history was taken from all women and note of folic acid supplementation made. A total of $5 \mathrm{ml}$ of venous blood was collected from antenatal women between 14-24 weeks of gestational age under aseptic precautions. Two $\mathrm{ml}$ was collected in EDTA vials for DNA extraction and genetic analysis and three $\mathrm{ml}$ in plain vials for evaluation of serum Homocysteine levels. The samples in plain vials were immediately centrifuged at $2000 \mathrm{rpm}$ in 'Spermfuge' and serum transported to laboratory at CDRI Lucknow, maintaining a proper cold chain.

\section{Homocysteine estimation}

The quantitative assessment of homocysteine was done using kit which was based on an enzymatic reaction which involves the principle of adsorption with the decrease in absorbance value of the sample at $340 \mathrm{~nm}$ due to oxidation of NADH to $\mathrm{NAD}^{+}$. The estimated values of homocysteine are directly proportional to the quantity of NADH oxidised. Value of homocysteine level in serum above $15 \mu \mathrm{mol} / \mathrm{L}$ was used to define hyperhomocysteinemia.

\section{Genetic analysis}

The point mutation $(677 \mathrm{C}>\mathrm{T})$ in the MTHFR gene was typed using direct DNA sequencing technique. Briefly, primers around the polymorphic site were designed with the help of GENETOOL software. PCR was carried out. The amplified products were directly sequenced using BigDye $^{\text {TM }}$ chain termination chemistry on ABI 3730 DNA analyzer (Applied Biosystems, USA). Multiple alignment and sequence analysis was done using Auto Assembler Software (Applied Biosystems, USA).

\section{Follow up}

The women were followed throughout the pregnancy and a note made of obstetric complications like miscarriage, pre-eclampsia, fetal growth restriction, abruptionplacentae, hypothyroidism and preterm labour. The definition of above complications was taken as follows:

- Miscarriage: Miscarriage defined as loss of a fetus before the 20th week of pregnancy.

- Pre-eclampsia: Defined as hypertension $\geq 140 / 90$ $\mathrm{mmHg}$ and proteinuria of $\geq+1$ after 20 weeks of gestation in previously normotensive women.

- Fetal growth restriction: Defined as a weight below the 5th percentile for the gestational age. ${ }^{10}$

- Abruptio-placentae: Abnormal separation of placenta after 20 weeks of gestation and prior to birth.

- Hypothyroidism: Serum TSH levels more than 3 $\mathrm{mIU} / \mathrm{ml}$ was taken as hypothyroidism.

- Preterm delivery: Defined as the birth of a baby of between 20 to 37 weeks gestational age.

Perinatal complications like presence of congenital malformations, small for gestational age, need for resuscitation, NNU admissions and neonatal hyperbilirubinemia were also noted.

\section{Statistical method}

The statistical analysis was done using SPSS (Statistical Package for Social Sciences) Version 15.0 statistical Analysis Software. The values were represented in Number $(\%)$ and Mean \pm SD.

The chi-square test was used to determine whether there was a significant difference between the expected frequencies and the observed frequencies in one or more categories.

\section{RESULTS}

The study was conducted in the Department of Obstetrics and Gynaecology, KGMU. A total of 90 antenatal women were enrolled in the study, however only 81 could be 
followed throughout the pregnancy and hence final analysis was done in 81 women.

Mean serum homocysteine level in pregnant women was $16.03 \pm 2.37 \mu \mathrm{mol} / \mathrm{l}$. To study the relation of homocysteine levels with complications the women were divided in two groups. Group 1 included women with no complication in present pregnancy and group 2 included women with at least one antenatal or perinatal complication. Group I had 42 women and Group II had 31 women. Mean homocysteine level in group I was $15.94 \pm 2.90 \mu \mathrm{mol} / \mathrm{l}$ and in Group II was $16.32 \pm 2.17 \mu \mathrm{mol} / \mathrm{l}$, both these levels were statistically not significant $(p=0.403)$. In both the groups, percentages of vegetarian were almost equal (61.9\% in group I and $54.6 \%$ in Group II). In group I, folic acid supplementation was $30.9 \%$ and in Group II, it was $53.8 \%$.

The association between the homocysteine levels in various complication subgroups against the mean homocysteine levels obtained from group 1 (15.94 \pm 2.90 $\mu \mathrm{mol} / \mathrm{L})$ is evaluated in Table 1 . Mean homocysteine levels of complications subgroups were not statistically different from the mean level obtained in group 1.

Table 1: Mean homocysteine level in women with different pregnancy complication.

\begin{tabular}{|c|c|c|c|}
\hline Complication & $\mathbf{N}$ & $\begin{array}{l}\text { Mean } \\
\text { Homocysteine } \\
(\mu \mathrm{mol} / \mathrm{l})\end{array}$ & Significance \\
\hline IUGR & 7 & $15.80 \pm 2.75$ & $\begin{array}{l}\mathrm{t}=0.079 \\
\mathrm{p}=0.937\end{array}$ \\
\hline Hypothyroidism & 6 & $15.02 \pm 2.35$ & $\begin{array}{l}t=0.706 \\
p=0.484\end{array}$ \\
\hline Preeclampsia & 14 & $17.19 \pm 1.84$ & $\begin{array}{l}t=1.562 \\
p=0.124\end{array}$ \\
\hline Preterm & 9 & $16.37 \pm 2.00$ & $\begin{array}{l}t=0.602 \\
p=0.550\end{array}$ \\
\hline Others & 9 & $15.64 \pm 2.20$ & $\begin{array}{l}\mathrm{t}=0.242 \\
\mathrm{p}=0.810\end{array}$ \\
\hline
\end{tabular}

Other complications included 2 women with hyperemesis gravidarum, one each with abruption placenta and placenta previa, one each with jaundice, oligoamnios, and bronchial asthma. There were two women with twin pregnancy, Our study also looked for MTHFR gene polymorphism $677 \mathrm{C}>\mathrm{T}$ in the patients. CC genotype was seen in 27 women in group I (64.28\%) and $28(71.9 \%)$ women in group II while CT and TT genotype was present in $13(30.9 \%)$ and $2(4.76 \%)$ in group I and 10 $(25.64 \%)$ and $1(2.57 \%)$ respectively. There was no statistically significant difference between the 2 groups in terms of genotypes.

Mean homocysteine levels were higher in women with TT genotype (16.95 $\mu \mathrm{mol} / \mathrm{l}$ in group I and $18.4 \mu \mathrm{mol} / \mathrm{l}$ in group II) as compared to other genotypes. However the number was very small and hence it is difficult to interpret its statistical significant relationship with complications in pregnancy.

\section{DISCUSSION}

Homocysteine is a sulfhydryl amino acid derived from the metabolic conversion of methionine, which is dependent on several enzymes and vitamins. Blood concentrations of homocysteine are determined by various dietary factors, including folic acid and vitamin $\mathrm{B}_{12}$, by alteration in physiology, such as renal impairment, and by variation in the activity of enzymes in the various pathways as a result of genetic polymorphisms, some of which are commonly found in the population. Hyperhomocysteinemia has been associated with vascular disease, although whether it is cause or effect is still a matter of debate. Disturbance of maternal and fetal homocysteine metabolism has been associated with fetal neural tube defects and with various conditions characterized by placental vasculopathy, such as pre-eclampsia, abruption, and recurrent pregnancy loss.

Several studies have found a positive correlation between homocysteine levels and pregnancy complications. It has been found that elevated levels of circulating homocysteine are a risk factor for endothelial dysfunction and vascular disease which is the most popular hypothesis for the etiopathogenesis of pre-eclampsia. Sorensen et al found that second trimester elevation of homocysteine was associated with 3.2 fold increased risk of pre-eclampsia. ${ }^{11}$ Acilmis et al concluded that maternal and fetal serum homocysteine levels were found to be significantly higher in severe pre-eclampsia group compared to mild pre-eclampsia and control groups suggesting that elevated serum levels of homocysteine might be associated with severity of pre-eclampsia. ${ }^{12}$

It has been hypothesized that in vitro, homocysteine enhances spontaneous contractions of myometrium. Applying the same it has been postulated that high homocysteine in early pregnancy leads to preterm labour. Murphy et al showed that raised homocysteine is associated with preterm delivery and also Vollset et al reported a strong association of preterm labour and homocysteine measured either before or after pregnancy. ${ }^{2,13}$ Similarly in our study the mean homocysteine level in subjects having preterm labour was $16.37 \mu \mathrm{mol} / \mathrm{L}$ which was higher than normal levels but a statistically significant relation could not be established $(\mathrm{OR}=1.00$,95\% CI: 0.23-4.34).

In this study homocysteine level in subjects with IUGR is lower than normal subjects but not significant statistically (OR=0.64,95\%CI: 0.13-3.09). Infante-Rivard et al also showed, there was an inverse association between plasma homocysteine and the risk of IUGR. ${ }^{14}$ Contrary to our study Jan Urban et al found that mean homocysteine level in group with IUGR was $11.5 \mathrm{ng} / \mathrm{dl}$, significantly higher than in normal pregnancy $(9.5 \mathrm{ng} / \mathrm{dl}) .{ }^{15}$ 
In present study subjects who had hypothyroidism had lower mean homocysteine level than normal, though it was not statistically significant $(\mathrm{OR}=1.0,95 \%$ CI: 0.17 5.84). Against our study Catarqi et al in 1999 found that homocysteine level to be elevated in hypothyroid cases. ${ }^{16}$ They postulated that hypothyroidism decreases hepatic levels of enzymes involved in remethylation pathway of homocysteine. Similarly Diekman et al concluded that plasma homocysteine levels increased in hypothyroidism. $^{17}$

Vollset et al investigated associations between tHcy and complications and adverse outcomes of pregnancy. ${ }^{2}$ When they compared the upper with the lower quartile of plasma tHcy, the adjusted risk for preeclampsia was $32 \%$ higher [odds ratio (OR): 1.32; 95\% CI: 0.98, 1.77; $P$ for trend $=0.02$ ], that for prematurity was $38 \%$ higher (OR: $1.38 ; 95 \%$ CI: $1.09,1.75 ; P$ for trend $=0.005)$, and that for very low birth weight was $101 \%$ higher (OR: 2.01; 95\% CI: $1.23,3.27 ; P$ for trend $=0.003)$. When the cut off value of homocysteine was taken as $15 \mu \mathrm{mol} / \mathrm{L}$ as quoted by Vollset we found that in $93.3 \%$ of cases of preeclampsia there was hyperhomocysteinemia which was statistically significant $(\mathrm{p}=0.044)$ rest other complications had not shown any statistical significant association with hyperhomocysteinemia.

Murphy et al in 2004 reported that elevated total plasma homocysteine during pregnancy has been associated with adverse pregnancy outcomes. ${ }^{13}$ Bergen et al concluded that higher homocysteine concentration in early pregnancy have higher risk of adverse pregnancy outcome. ${ }^{18}$ Refsum $\mathrm{H}$ reported that women having high homocysteine levels are at increased risk of pregnancy complications and adverse pregnancy outcome. ${ }^{19}$ However, none of these studies tested the accuracy of a defined cut-off value for prediction of pregnancy complications with an adequate accuracy. In our study too mean homocysteine level of subjects with complication in present pregnancy is higher than subjects with no complication but the difference is not significant statistically. This is probably due to small number of women with different complications in this study.

\section{CONCLUSION}

Despite the fact that significant difference in mean homocysteine levels in women with pregnancy complications and those without pregnancy complications has been seen in various studies, it is still not known if there is a cut-off value that could predict pregnancy complications with adequate accuracy. In Indian context with wide spread nutritional deficiencies, it is difficult to comment if high prevalence of hyperhomocysteinemia is a measure of nutritional deficiency. It is suggested that a larger trial be under taken in India as there is high prevalence of hyperhomocysteinemia to understand its causes, and any association with pregnancy complications.

\section{ACKNOWLEDGEMENTS}

Authors are greteful to Council of Scientific and Industrial Research for financially supporting the research (Project code BSC 0101). Authors would also wish to acknowledge Ms Mohini Chhabra for her help in conducting the experiments.

Funding: No funding sources

Conflict of interest: None declared

Ethical approval: The study was approved by the Institutional Ethics Committee

\section{REFERENCES}

1. Malinow MR, Bostom AG, Krauss RM. Homocysteine, diet and cardiovascular diseases: a statement for healthcare professionals from nutrition committee, American Heart Association. Circulation. 1999;99:178-82.

2. Vollset SE1, Refsum H, Irgens LM, Emblem BM, Tverdal A, Gjessing $\mathrm{HK}$ et al. Plasma total homocysteine, pregnancy complications and adverse pregnancy outcomes: The Hordaland Homocysteine study. Am J Clin Nutr. 2000;71:962-8.

3. Ray JG, Laskin CA. Folic acid and homocysteine metabolic defects and the risk of placental abruption, preeclampsia, and spontaneous pregnancy loss: a systematic review. Placenta. 1999;20:519-29.

4. Burke G, Robinson K, Refsum H, Stuart B, Drumm J, Graham IN. Intrauterine growth retardation, perinatal death, and maternal homocysteine levels. Engl J Med. 1992;326(1):69-70.

5. Steegers-Theunissen RP, Boers GH, Blom HJ, Trijbels FJ, Eskes TK. Hyperhomocysteinemia and recurrent spontaneous abortion or abruptio placentae. Lancet. 1992;339(8801):1122-3.

6. Wouters MGAJ, Boers, GHJ, Blom, HJ, Trijbels, FJM, Thomas, CMG, Borm, GF et al. Hyperhomocysteinemia: a risk factor in woman with unexplained recurrent early pregnancy loss. Fertil. Steril. 1998;60:820-5.

7. Dekker GA, de Vries JI, Doelitzsch PM, Huijgens $\mathrm{PC}$, von Blomberg BM, Jakobs C et al. Underlying disorders associated with severe earlyonset preeclampsia. Am J Obstet Gynecol. 1995;173:1042-8.

8. Goddijn-Wessel TA, Wouters MG, van de Molen EF, Spuijbroek MD, Steegers-Theunissen RP, Blom HJ et al. Hyperhomocysteinemia: a risk factor for placental abruption or infrarction, Eur J Obstet Gynecol Reprod Biol. 1996;66(1):23-9.

9. Abbassi-Ghanavati M, Greer LG, Cunningham FG. Pregnancy and Laboratory Studies: A reference table for clinicians. Obs. \&Gyne. 2009;114(6):1326-31.

10. Seeds JW. Impaired fetal growth definitions and clinical diagnosis. Obstetrics Gynecology. 1984;64(3):303.

11. Sorensen TK, Malinow MR, Williams MA, King IB, Luthy DA. Elevated second trimester serum homocysteine levels and subsequent risk of 
preeclampsia. Gynecol Obstet Invest. 1999;48(2):98103.

12. Acilmis YG, Dikensoy E, Kutlar A, Balat O, Cebesoy FB, Ozturk E et al. Homocysteine, folic acid and vitamin B12 levels in maternal and umbilical cord plasma and homocysteine levels in placenta in pregnant woman with pre-eclampsia. J Obstet Gynaecol. 2011;37:45-50.

13. Murphy MM, Scott JM, Arija V, Molloy AM, Ballart JDF. Maternal Homocysteine before Conception and throughout Pregnancy Predicts Fetal Homocysteine and Birth Weight. Clin Chem. 2004;50(8):1406-12.

14. Infante-Rivard C, Rivard GE, Yotov WV, Genin E, Guiguet M, Weinberg C et al. Absence of association of thrombophilia polymorphisms with intrauterine growth restriction. N Engl J Med. 2002;347:19-25.

15. Urban J, Jarocki S, Bielecki D, Urban R. Serum homocysteine and nitric oxide levels in pregnancy complicated with intrauterine fetal growth restriction A P Med. 2007;13(3):27-9.

16. Catarqi B, Parrot-Roulaud F, Cochet C, Ducassou D, Roger $\mathrm{P}$ et al. Homocysteine, Hypothyroidism, and effect of thyroid hormone replacement Thyroid. 1999;9(12):1163-6.

17. Diekman MJM, Van Der Put NM, Blom HJ, Tijssen JGP, Wiersinga WM. Determinants of changes in plasma homocysteine in hyperthyroidism and hypothyroidism. Clinical Endocrinology. 2001; 54(2):197-204.

18. Bergen NE, Jaddoe VW, Timmermabs S, Hofman A, Lindemans J, Russcher $\mathrm{H}$ et al. Homocysteine and folate concentrations in early pregnancy and the risk of adverse pregnancy outcomes: the Generation $\mathrm{R}$ Study. BJOG. 2012;119(6):739-51.

19. Refsum H. Folate, vitamin B12 and homocysteine in relation to birth defects and pregnancy outcomes. BJ N. 2001;85:S109-13.

Cite this article as: Jaiswal N, Agrawal A, Agrawal S, Das V, Pandey A, Singh R. Correlation of serum homocysteine levels and pregnancy outcome: the dilemma continues. Int J Reprod Contracept Obstet Gynecol 2016;5:391-5. 